\title{
Comprehensive Outcome of Repair of Small Paraumbilical Hernias by Onlay Mesh Hernioplasty under Local Anesthesia
}

\author{
Ch Mohammad Kamran ${ }^{1}$, Balakh Sher Zaman ${ }^{2 *}$ and Maryam Wahid ${ }^{3}$ \\ ${ }^{1}$ Associate Professor, Department of Surgery, Allama Iqbal Medical College, Pakistan \\ ${ }^{2}$ Assistant Professor, Department of Surgery, King Edward Medical University, Pakistan \\ ${ }^{3}$ Head of Biochemistry, Department Foundation, University Medical College, Pakistan
}

Received: May 12, 2019; Published: June 25, 2019

*Corresponding author: Balakh Sher Zaman, Assistant Professor, Department of Surgery, MBBS, FCPS, MRCS(London), MRCS(Glasg), King Edward Medical University, Lahore, Pakistan

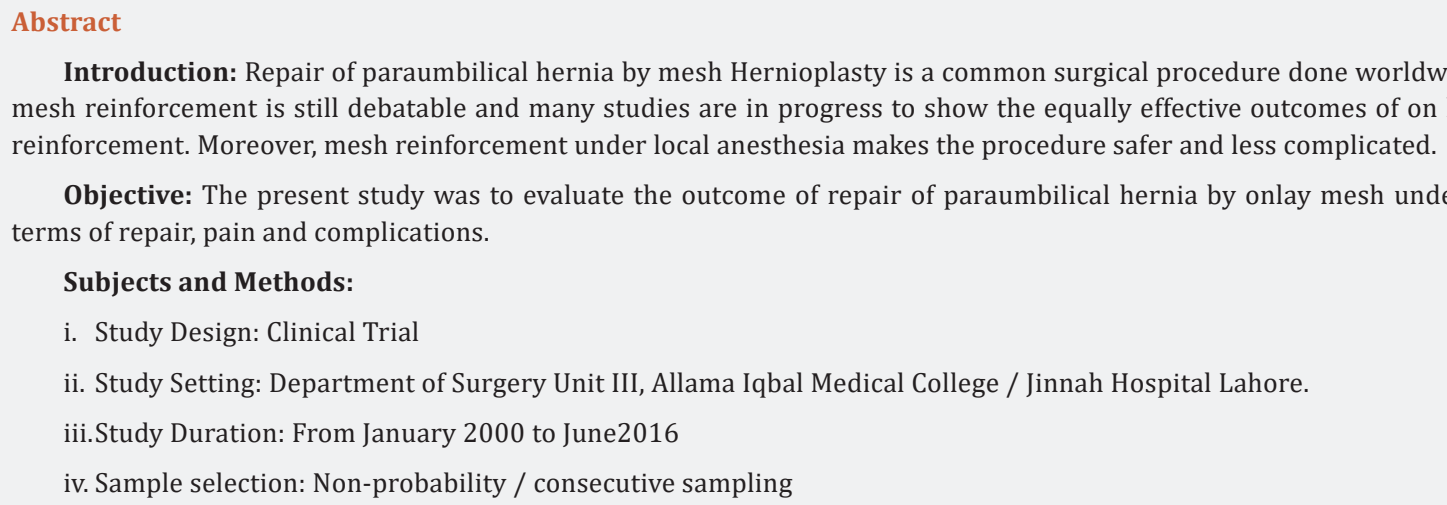
reinforcement. Moreover, mesh reinforcement under local anesthesia makes the procedure safer and less complicated. terms of repair, pain and complications.

Subjects and Methods:

i. Study Design: Clinical Trial

ii. Study Setting: Department of Surgery Unit III, Allama Iqbal Medical College / Jinnah Hospital Lahore.

iii.Study Duration: From January 2000 to June2016

iv. Sample selection: Non-probability / consecutive sampling

Introduction: Repair of paraumbilical hernia by mesh Hernioplasty is a common surgical procedure done worldwide. The ideal site for mesh reinforcement is still debatable and many studies are in progress to show the equally effective outcomes of on lay and sub lay mesh

Objective: The present study was to evaluate the outcome of repair of paraumbilical hernia by onlay mesh under local anesthesia in

v. Data Collection and analysis: A prospective non-randomized clinical trial done. Sample size was 500 patients (350 females and 150 males) age ranging from 25 to 75 years. Patients having small paraumbilical hernia of $0.5-4 \mathrm{~cm}$ abdominal wall defects, which were repaired by onlay mesh reinforcement using prosthetic prolene mesh under local anesthesia. Outcome was measured in terms repair, pain at incision site at 6 and 12 hours and complications. Data was entered and analyzed in SPSS ver: 21.0 and outcome was presented as frequency and percentages.

Results: Out of 500 patients, 120 patients (95 females and 25 males) had chronic liver disease and ascites. 35 had oozing of serous discharge from the hernia. Females included multiparous $93 \%$, primiparous $6 \%$ and nulliparous $1 \%$ were most affected $(70 \%$ females \& $30 \%$ males). Mean age of the patients were $43+11.01$ years $(p<0.05)$. Post-operative pain measures on VAS were $2+0.45$ at 12 hours.1.6\% (08) patients developed Seroma and $1.0 \%(05)$ had wound infections.

Conclusion: Onlay mesh reinforcement under local anaesthesia was found to be safer, cost effective, associated with minimum chance of post-operative complications and early return to normal life.

\section{Introduction}

Umbilical and para-umbilical hernia is becoming a relatively common surgical issue. Studies have shown the rising trend in UK [1] i.e. from $5 \%$ to $14 \%$ as well as in Turkey [2]. Abnormal protrusion of abdominal contents, mesenteric fat, intestines through a weaker area in the anterior abdominal wall closes to umbilicus is called paraumbilical Hernia. Weak spot may result due to defect in the anterior abdominal muscles, rectus sheath or ligaments. The defect may be congenital or acquired
[3]. Hernial contents squeeze through the weak spot in the form of protruding hernia sac. Its common complications are strangulation or intestinal obstruction. Commonly women are more prone to develop para umbilical hernias as compared to males. Patients usually present with a visible lump around navel.

They approach the surgeons when pain starts, and surgical repair is required. This condition usually becomes painful contents are trapped in the hernial sac leading to palpable lump 
requiring surgical intervention. Surgical treatment may involve various methods which follow some common basic strategies $[4,5]$. Basic strategy involved is inversion of hernia sac contents back to the cavity they normally belong then weak spot can be stitched (herniorraphy) or reinforced (Hernioplasty) and hernia is repaired. Most commonly employed surgical intervention involves the closure of weak spot along with insertion of mesh to reinforcement the defective area (Hernioplasty) hence the recurrence chance is minimized. Mesh placement may be done onlay (on anterior rectus sheath) or sublay (below rectus muscles on to the posterior rectus sheath) [6]. Onlay mesh is considered to be a tension free method for repair of abdominal wall defects.

Literature review revealed that several studies declared the onlay mesh reinforcement technique as the best option and this is the most commonly performed technique worldwide. Several studies have compared onlay mesh reinforcement with sublay technique and rated the second one as a poor technique [7]. However, the ideal site for mesh reinforcement is still debatable and many studies are in progress to show the equally effective outcomes of onlay and sublay mesh reinforcement and reach an acceptable conclusion [8]. Though its incidence has been increased since the last two decades (1991 - 2010, there still seems to be a lack of attention given to this issue in research fields and literature [9]. However, it is the need of time to probe into the problem and find out the most appropriate para umbilical hernia repair options. Keeping above in view, the present study was also planned to explore the effectiveness and failure rate of onlay mesh under local anaesthesia to reinforce the defect causing paraumbilical hernia.

\section{Objective}

The objective of the study was to determine the outcome of onlay mesh reinforcement for repair of paraumbilical hernia under local anesthesia.

\section{Methodology}

Present study was carried in the Department of General Surgery Jinnah Hospital Lahore as well as in private hospitals of Lahore from 2000 to 2016. It was a prospective non-randomized clinical trial. Total of 500 patients (350 females and 150 males) age ranging from 25 to 75 years were operated. Patients were randomly selected having small paraumbilical hernia of 0.5 - 4 $\mathrm{cm}$ abdominal wall defects and requiring surgical intervention. Their written consent was taken. Before surgery thorough preoperative evaluation with the help of urinalysis, blood complete picture (CP) and abdominal ultrasound was done. Patients with chronic liver disease (CLD) were also investigated for coagulation profile and arrangement of fresh frozen plasma (FFP) transfusion was made before the start of surgery.

Every patient received prophylactic intravenous antibiotic at the time of local anaesthesia infiltration in the operation theatre. Area to be operated was cleaned with antiseptics and intravenous line was maintained with Ringer lactate infusion. $0.5 \%$ lignocaine $(10 \mathrm{ml})$ with $50 \mathrm{mg}$ Bupivacaine $(10 \mathrm{ml})$ was used for infiltration anaesthesia. $130 \mathrm{ml}$ normal saline was added to these two ampoules of lignocaine and of Bupivacaine $(10 \mathrm{ml}$ each). Hence total volume of infiltrate was $150 \mathrm{ml}$. Then $0.5 \mathrm{ml}$ of adrenaline 1/1000 was also added and the total adrenaline concentration was $1 / 400,000$ in $150 \mathrm{ml}$ which was safe and did not affect vital signs like pulse and blood pressure. Adrenaline led to minimum bleeding when incision was given. Most of the time 70 to $100 \mathrm{ml}$ of local anaesthetic solution was sufficient to carry painless surgery.

Local anaesthesia infiltration was started from the site of incision, area around the umbilicus and below the site of incision. Syringe $(10 \mathrm{cc})$ with $27 \mathrm{G}$ needle was used for infiltration purpose. The infiltration was done at a slow rate because rapid infiltration may lead to acute pain. No Sedative was added except a single intramuscular dose of nalbuphine $20 \mathrm{mg}$, a centrally acting opioid analgesic. Material used for reinforcement was synthetic material prolene mesh (Ethicon made) which is a derivative from polypropylene. The procedure comprised of open access to abdominal cavity, squeezing back the contents of the hernial sac (sometimes sacs were opened too) and defect was closed with proline No. 1 before mesh placement. The prolene mesh was placed over the rectus sheath defect overlapping $4 \mathrm{~cm}$ from each side in such a way that it completely covers the prevailing defect. Umbilicus was attached with the sheath and normal shape of umbilicus restored. Whereas in most of the patients with CLD, umbilicus had to be removed (umbilectomy) because in ascites the skin overlying the paraumbilical hernia and around umbilicus was of poor quality thus hampering the proper closure of wound.
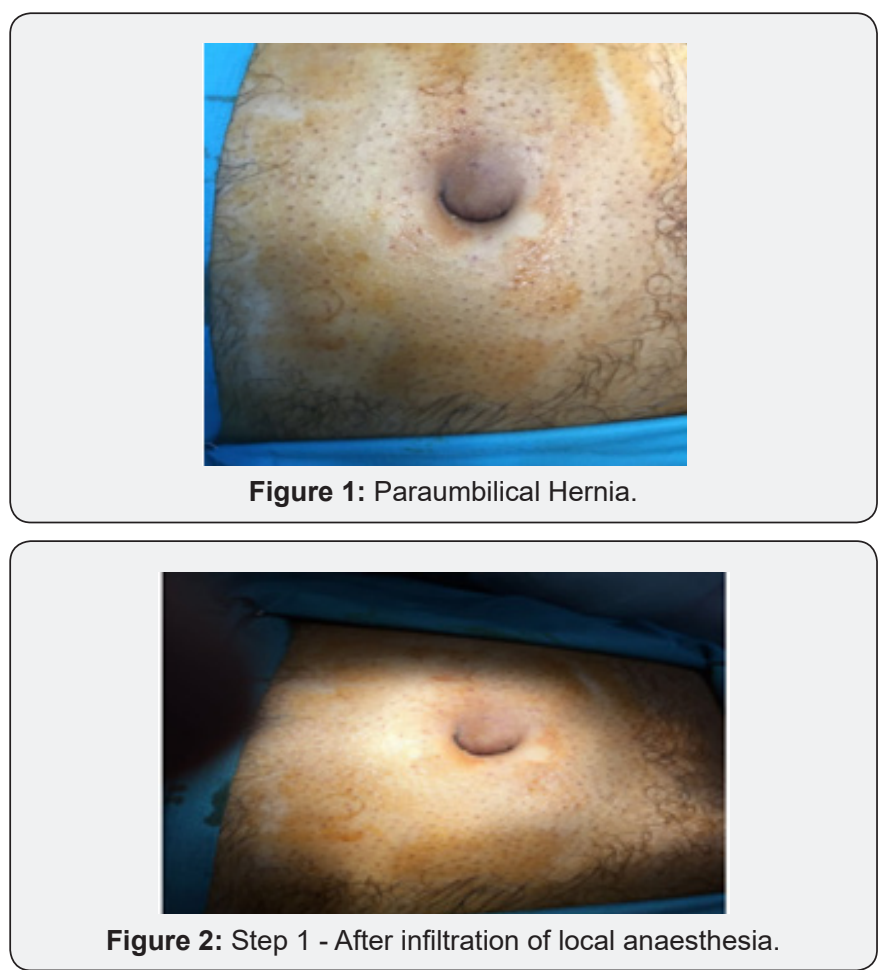


\section{Open Access Journal of Surgery}

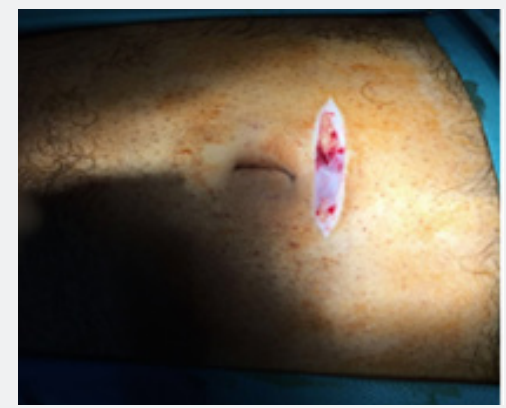

Figure 3: Step 2 - Supraumbilical incision was given. No bleeding was observed.

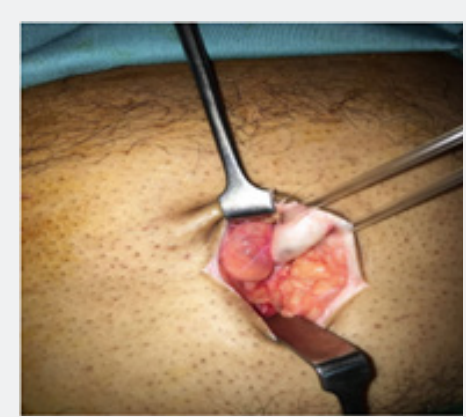

Figure 4: Step 2 - Supraumbilical incision was given. No bleeding was observed.

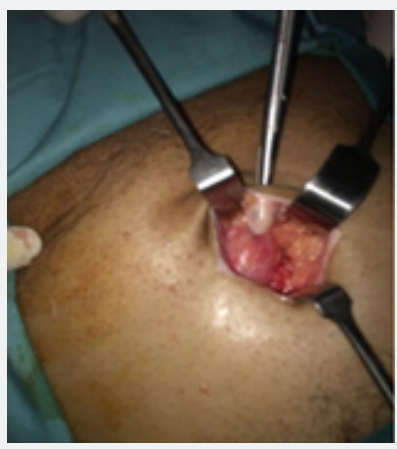

Figure 5: step 4-the sac was visible. It was separated from the umbilicus and was pushed back along with contents.

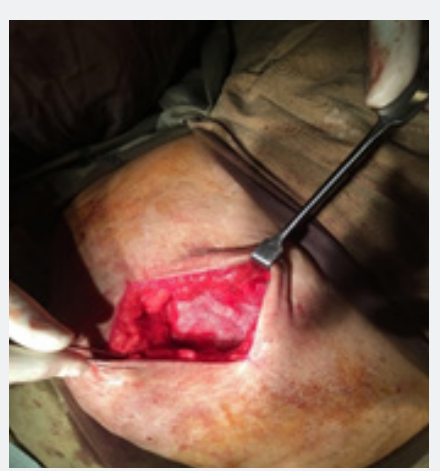

Figure 6: step 5 - Onlayprolene mesh was placed and fixed with permanent sutures.

Finally, the skin was closed with subcuticular type Vicryl $4 / 0$ sutures, so no outpatient visit was required for removal of stitches. Various steps of the surgical procedures are being shown in Figures 1-8. For the repair of defects less than $2 \mathrm{~cm}$, no suction drain was required. Whereas postoperatively Redivac drain was put in $30 \%$ (155 out of 500 patients), which was removed on 3rd to 5 th day. The whole Anesthetist remained in the theater throughout the length of procedure. During surgery, patients were comfortable and hemodynamically stable with all vital signs within normal range. All the surgeries completed in $40 \mathrm{~min}(+/-15 \mathrm{~min})$. During this time, no further medication was required or added. All patients were given appropriate antibiotics for five days after the surgery.

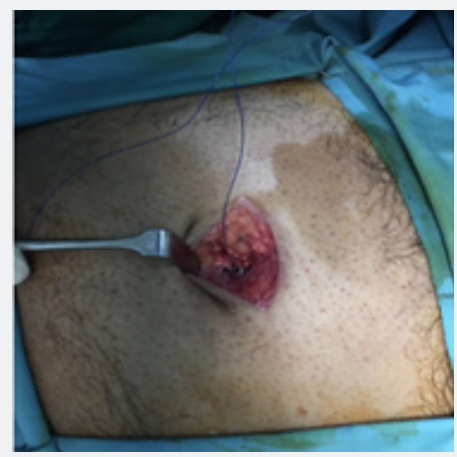

Figure 7: step 6 - defect was closed with prolene No 1.

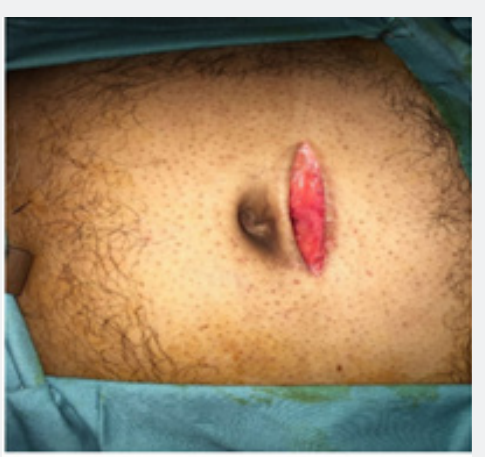

Figure 8: Wound was closed by subcuticular stitches.

\section{Results}

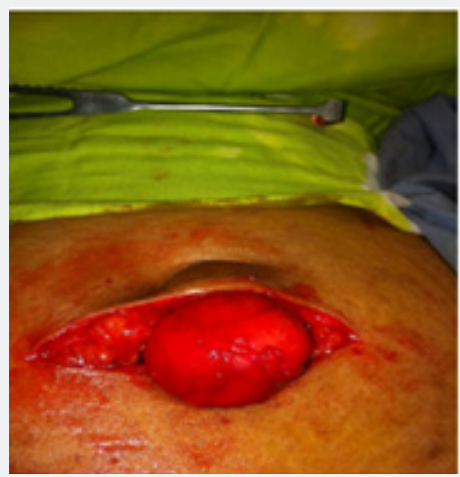

Figure 9: Exposed hernial sac in a patient with CLD and ascites.

Five hundred patient were included in the study out of which 120 patients ( 95 females and 25 males) presented with chronic liver disease and ascites creating pressure in abdomen 
leading to hernia shown in (Figures $9 \& 10$ ). 35 patients with ascites showed oozing of thin serous discharge from the hernial site. In the sample, 93\% females were multiparous, $6 \%$ were primiparous and $1 \%$ nulliparous due to some primary infertility related issue. Statistical analysis revealed that paraumbilical hernia was more commonly seen in females $(70 \%$ females \& $30 \%$ males) and mean age of developing this condition was $43+$ 11.01 years $(\mathrm{p}<0.05)$.

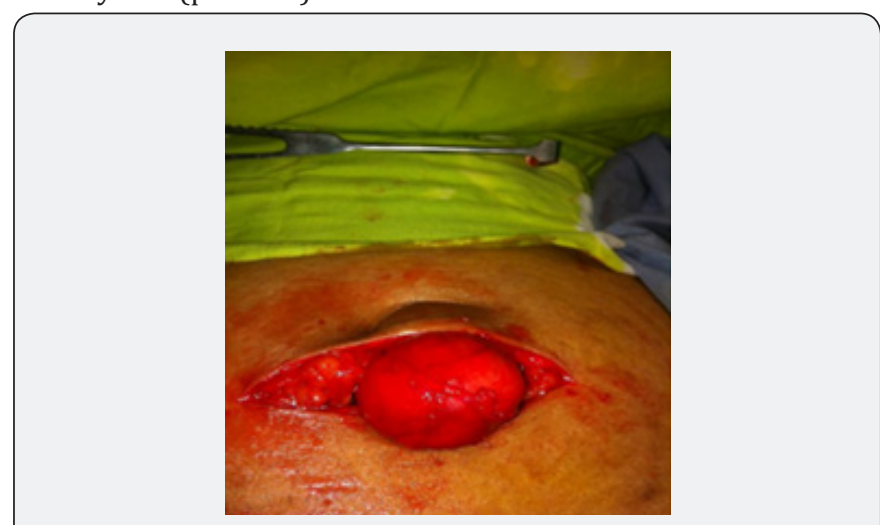

Figure 10: Paraumbilical hernia in a patient with CLD and ascites. In this case Umbilectomy was done.

Post-operative pain scale was zero i.e. no pain at all, for the initial 6-8 hours and even afterwards scale did not exceed 3 (barely noticeable) i.e. $2+/-0.45$ at 12 hours for which patients were advised to take tablet paracetamol and naproxen orally. Most of the operated patients did not develop any post-operative complication and were satisfied of the selected surgical procedure. However, 1.6\% (08) patients developed Seroma which was managed by simple aspiration and $1.0 \%(05)$ patients developed wound infection which responded to appropriate antibiotics prescribed after culture and sensitivity test. None of the patients needed mesh removal to control the infection.

\section{Discussion}

Paraumbilical hernia is very frequently encountered surgical issue affecting females at a higher rate as compared to males and our study also supported this trend. Multiparous elderly females were found to be the most frequent victims of this condition [10]. Literature review revealed that for the past few years the trend for mesh reinforcement hernioplasty is increasing as compared with non-mesh-based repair [11]. A randomized clinical trial and 64 months post-operative follow up also revealed that there are less chances of recurrence if hernia repair is done with mesh $(\sim 1 \%)$ as compared to repair with sutures ( 11\%) [12].

However, the best site for inserting the materials for mesh reinforcement has not been convincingly established till date [13]. Best site for reinforcement would be the one which is simple, least painful, causes minimum discomfort during and after the procedure, has minimum chances of recurrence and least vulnerable to infections [14]. Early methods employed for hernia repair like suturing, manipulation of anatomical structures led to high tension on tissues surrounding the site leading to high rate of recurrence $[15,16]$. We used conventionally woven polypropylene (prolene) mesh for tension free repair of paraumbilical hernia. Prolene is a synthetic non absorbable material composed of crystalline stereoisomers of polypropylene unsaturated bonds. It possesses greater tensile strength, passes smoothly from the tissues to be repaired and induces minimum antigenic foreign body response. Moreover, it doesn't adhere to the surrounding tissues [17].

Onlay mesh was inserted above the rectus sheet to provide additional support to weaker area and repair the small paraumbilical hernias. Interestingly the recovery process in operated patients was rapid, pain scale was $0-1$ as muscles were not pulled together or stitched under tension. Patients returned to normal activity within 3-4 days and resumed their jobs and even recreational activities within 4-6 days. One month follow up confirmed the success of onlay mesh as there was no recurrence. Studies have proved that if polypropylene mesh was inserted intraperitoneally, most of the time it led to complications during and after the surgery [18]. Another study selected sublay mesh plasty to treat various types of hernia including paraumbilical and found this technique a better option with minimum chances to develop infection [19]. Whereas in present study the mesh was placed above rectus sheath (onlay) with negligible number of complications of seroma and wound infection on follow up.

Prolene mesh is the most commonly applied prosthetic mesh and we also used this mesh for open onlay repair. As prolene mesh induced less tissue rejection response, showed minimum shrinkage thus better for onlay repair. As 120 patients presented with chronic liver disease and uncontrolled ascites being the most common threat for recurrence. Studies have shown that more than $20 \%$ patients with ascites develop paraumbilical hernia and hernia sac contains ascitic fluid in addition to abdominal cavity contents like peritoneum, omentum and intestines. In these patients Hernioplasty is difficult and mostly "wait and see" policy is followed. Fortunately, during one-month post-operative follow up no recurrence was observed.

Hence it can be safely claimed that early elective onlay mesh reinforcement can be planned to avoid emergency hernia repair due to any complication like strangulation enhancing morbidity and mortality in theses patient. However, ascites control should be strictly taken as a part of post-operative care. Moreover, as the surgery was performed under local anaesthesia, so patients started physical activities much earlier after surgery, minimum stay in the hospital and did not develop any complication related to general anaesthesia or spinal anaesthesia like urinary retention - a common hazard of old age surgeries.

\section{Conclusion}

Onlay mesh reinforcement under local anaesthesia can safely be used as a superior procedure to repair paraumbilical hernia as it was found to be cost effective, painless, quick and easy technique, with minimum chance of post-operative infection and 
thus recurrence. This study evidently overcomes the reluctance of surgeons to use onlay mesh reinforcement as a first choice to treat and repair small paraumbilical hernias.

\section{References}

1. Dabbas N, Adams K, Pearson K, Royle G (2001) Frequency of abdominal wall hernias: is classical teaching out of date? JRSM Short report 2: 5 .

2. Seker G, Kulacoglu H, Oztuna D, Topgul K, Akyol C, et al. (2014) Changes in the frequencies of abdominal wall hernias and the preferences for their repair: a multicenter national study from Turkey. IntSurg 99: $534-542$.

3. Muysoms FE, Miserez M, Berrevoet F, Campanelli G, Champault GG, et al. (2009) Classification of primary and incisional abdominal wall hernias. Hernia 13: 407 - 414.

4. Velasco M, Garcia - Urena M, Hidalgo M, Vega M, Carnero F (1999) Current concepts on adult umblical hernia. Hernia 3(4): 233 -239.

5. Arroyo A, Garcia P Perez F, Andreu J, Candela F, Calpena R (2001) Randomized clinical trial comparing suture and mesh repair of umblical hernia in adults. Br J Surg 88: 1321 - 1323.

6. Bowley D, Kingsnorth A (2000) umblical hernia, Mayo or mesh? Hernia 4: $195-196$

7. Wright BE, Beckerman J, Cohen M, Cumming JK, Rodriguez JL (2002) Is laparoscopic umblical hernia repair with mesh a reasonable alternative to conventional repair? Am J Surg 184: 505 - 508.

8. Kulacoglu H, Oztuna D (2011) Growth and trends in publlications about abdominal wall hernias and the impact of a specific journal on herniology: a bibliometric analysis. Hernia 15: 615 - 628 .

9. Rutkow IM (1998) Epidemiologic, economic and sociologic aspects of hernia surgery in the United States in the 1990s. SurgClin North Am 78: $941-951$.
10. Kulacoglu H, Yazicioglu D, Ozyaylali I (2012) Prosthetic repair of umblical hernias in adults with local anaesthesia in a day case setting: a comprehensivereport from a specialized hernia center. Hernia 16: 163 -170 .

11. Salameh JR (2008) primary and unusual abdominal wall hernias. SurgClin North Am 88: 45 - 60.

12. Burger JW, Luijendijk RW, Hop WC (2004) long term follow up of a randomized controlled trail of suture versus mesh repair of incisional hernia. Ann Surg 240: 578 - 583.

13. Martis JJ, Rajeshwara KV, Shridhar MK, Janardhanan D, Sudarshan S (2011) Strangulated Richter's umblical hernia - a case report. Indian J Surg 73: $455-457$.

14. Kurzer M, Belsham PA, Kark AE (2004) Tension free mesh repair of umblical hernias as a day case using local anaesthesia. Hernia 8(2): $104-107$.

15. Mackenzie D (1973) The history of sutures. Med Hist 17(2): 158 - 168.

16. Godara R, Garg P, Raj H, Singla SL (2006) Comparative evaluation of sublay versus onlaymeshplasty in ventral hernias. The Internal Journal of Surgery 8.

17. Halm JA, De Wall LL, Steyeberg EW, (2007) intra peritoneal polypropylene mesh hernia repair complicates subsequent abdominal surgery. World J Surg 31(2): 423-429.

18. Buffone A, Costanzo M, Basile G, Terranova L, Papa V, et al. (2012) Spontaneous rupture of an umbilical hernia in a cirrhotic patient with ascites; a case report and review of the literature. Ann Ital Chir e - publish.

19. Afridi SP, Siddiqui RA, Rajput A (2015) complications of onlay and sublay mesh plasty in ventral abdominal hernia repair. Journal of Surgery Pakistan 20(2): 48 - 51

\section{Your next submission with Juniper Publishers will reach you the below assets}

- Quality Editorial service

- Swift Peer Review

- Reprints availability

- E-prints Service

- Manuscript Podcast for convenient understanding

- Global attainment $f$ or your research

- Manuscript accessibility in different formats ( Pdf, E-pub, Full Text, Audio)

- Unceasing customer service

Track the below URL for one-step submission https://juniperpublishers.com/online-submission.php 